\title{
Encapsulated Data Text Data Type
}

National Cancer Institute

\section{Source}

National Cancer Institute. Encapsulated Data Text Data Type. NCI Thesaurus. Code C95652.

A data type comprised of encapsulated data in the form of text. 